\title{
KAJIAN PENAMBANGAN PASIR BESI MENGGUNAKAN MAGNETIC SEPARATOR PADA PT. BHINEKA BUMI KECAMATAN ADIPALA KABUPATEN CILACAP PROVINSI JAWA TENGAH
}

\author{
Abd.Rahim \\ Prodi Teknik Pertambangan, Politeknik Amamapare Timika \\ (Email:abd.rahim907@yahoo.com)
}

\begin{abstract}
ABSTRAK
Pasir besi merupakan salah satu bahan baku untuk semen selain gamping dam clay. Dalam upaya memenuhi kebutuhan semen baik yang berada di Pulau Jawa maupun di luar Pulau Jawa, PT. Bhineka Bumi berupaya mengeksploitasi cadangan pasir besi yang banyak terdapat di wilayah Kabupaten Cilacap. Tujuan dari penelitian ini yaitu Untuk mengetahui tahapan penambangan, mengetahui cara kerja alat untuk mengeksploitasi pasir besi serta mengetahui target produksi pasir besi dari alat magnetic separator. Metode penelitian ini yaitu studi literatur untuk mengetahui keadaan atau gambaran umum dilapangan, interview ke managemen teknik produksi agar mengetahui proses kegiatan dilapangan, observasi langsung untuk mengkorelasikan data metode penambangan dengan studi literature. Target produksi dari PT. Bhineka Bumi sendiri adalah 8.000-9.000 Ton/Bulannya. Dari hasil produksi perbulannya PT. Bhineka Bumi dapat menghasilkan 7.000-7.500 Perton konsentrat pasir besi, yang mana hasil produksi pasir besii PT. Bhineka Bumi disalurkan pada PT. Holcil Indonesia sebagai campuran semen.
\end{abstract}

Kata Kunci : Pasir besi, Magnetic, Separator

\section{PENDAHULUAN}

PT. Bhineka Bumi Merupakan yang bergerak pada bidang pertambangan bahan galian industry dan mengelola pasir besi sebagai salah satu pembuatan.

Pasir besi merupakan salah satu bahan baku untuk semen selain gamping dam clay. Kebutuhan pasir besi di Kabupaten Cilacap khususnya pabrik semen PT. Holcim sendiri membutuhkan sekitar 5.000 ton tiap bulannya. Dalam upaya memenuhi kebutuhan semen baik yang berada di Pulau Jawa maupun di luar Pulau Jawa,PT. Bhineka Bumi berupaya mengeksploitasi cadangan pasir besi yang banyak terdapat di wilayah Kabupaten Cilacap.

Wilayah eksplorasi PT. Bhinaka Bumi Berada di Pesisir Pantai selatan Pulau Jawa yang merupakan wilayah eks. Antam Blok D, namun Wilayah eksplorasi PT. Bhinaka Bumi belum pernah dieksplorasi oleh Antam, sehingga sumber daya pasir besi masih cukup layak untuk di upayakan penambangannya.

Dengan memanfaatkan transportasi laut ditanjung dengan adanya pelabuhan di Kabupaten Cilacap, penambangan dimudahkan dalam pengangkutan bahan tambang untuk penjualan luar Pulau Jawa. (Jumaida, dkk,2014)

\section{METODOLOGI}

Metode Penelitian adalah suatu kegiatan pengumpulan data yang berhubungan dengan kegiatan penelitian yang dilakukan yaitu:

1. Studi Literatur, dilakukan dengan mencari bahan - bahan pustaka yang menunjang baik yang bersifat pendukung dan referensi referensi.

2. Wawancara dilakukan bertujuan untuk mendapatkan informasi yang berkaitan dengan penelitian yang dilakukan. 
3. Observasi langsung, yaitu dengan melaksanakan aktifitas - aktifitas yang meliputi pengamatan langsung terhadap kondisi lapangan, pengambilan data dan pengumpulan data.

Sebelum dilakukan penelitian dan pengambilan data lapangan dimulai terlebih untuk senantiasa memperhatikan prosedur-prosedur agar penelitian dan kegiatan pengambilan data tersebut nantinya dapat berjalan dengan lancar dan tepat sebagaimana mestinya. Adapun prosedur-prosedur yang dilakukan di lapangan, antara lain: ( Rochman, dkk 2014)

1. Melihat dan mengamati aktifitas para pekerja yang mengatur system kelistrikan.

2. Membersihkan tempat hasil dari pengolahan agar tidak tercampur dengan pasir biasa.

3. Membersihkan kolam penampungan air agar tidak masuk dalam tempat penyemprotan pasir besi.

Metode dalam penelitian ini melihat proses penembangan serta menganalisa perbandingan logam pasir besi $(\mathrm{Fe})$ dengan non logam.

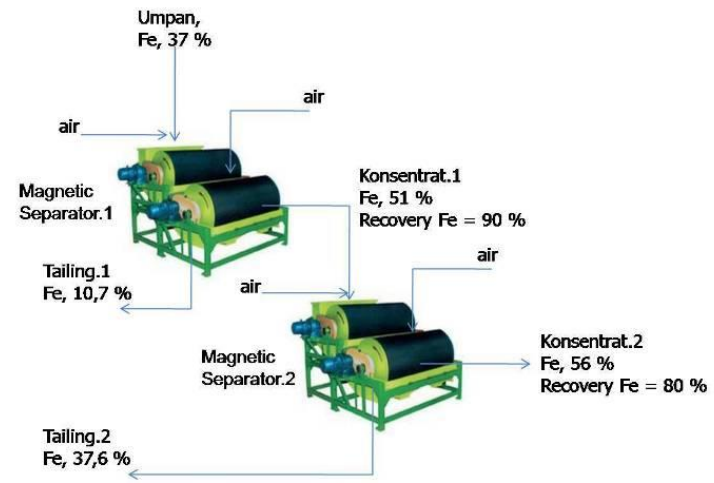

Gambar 1. Separator trap megnetit

\section{HASIL DAN PEMBAHASAN}

\section{A. Proses Penambangan Pasir Besi}

Penambangan pasir besi menggunakan system tambang semprot dengan air (hydroulid mining) dan pengisian kembali daerah-daerah yang telah digali/ditambang dengan material sisa penambangan (back filling). Dalam proses ini air digunakan sebagai media tranportasi pasir besi dari front tambang ke magnetic separator (MS) dan dari MS ke tailing pond, sebagai media pasir besi. Sebagian besar areal penambangan tidak ada penutup tanah, lapisan penutupnya dalam bentuk tanah halus yang mengandung pasir besi. Pada areal tertentu yang mempunyai tanah penutup perlu dilakukan land clearing dan lapisan penutup ditimbun pada suatu tempat untuk kemudian dikembalikan setelah selesai reklamasi.
Pembukaan lahan dilakukan seminimal mungkin, yaitu hanya pada areal yang akan ditambang. Proses penambangan pasir besi dilakukan block per block dengan ukuran $20 \times 50$ meter dengan kedalaman sampai dengan 6 meter (sesuai data eksplorasi). Setelah blok - blok selesai ditambang, air ditampung pada kolong bekas penambangan dan dimanfaatkan kembali untuk penambangan dan pemisahan berikutnya.

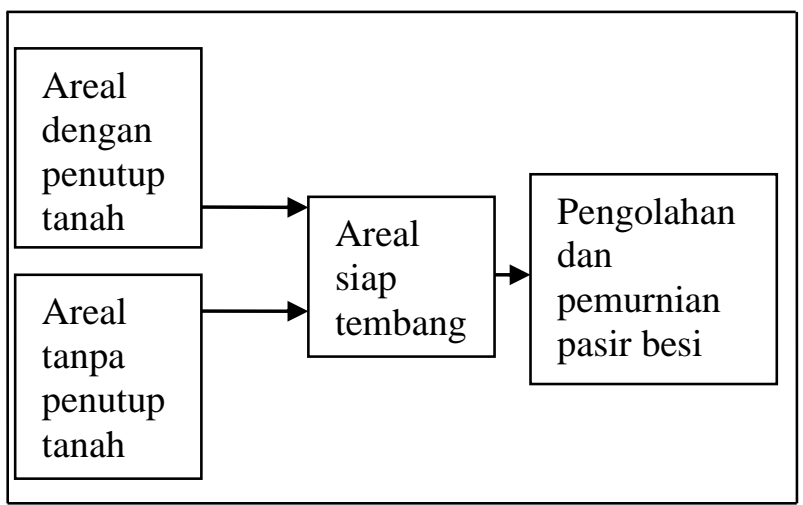

Gambar 2. Proses Penambangan Pasir Besi

\section{B. Proses Pengolahan dan Pemurnian Pasir besi}

Untuk menghasilkan konsentrat pasir besi dilakukan pengolahan dengan menggunakan magnetic separator (MS), yaitu memisahkan pasir basi (megnetit) dengan pasir biasa (non magnetic) dengan menggunakan tenaga dari listrik PLN. Terdapat beberapa tahap pemisahan, yaitu :

a. Awalnya pemasangan semua peralatan penambangan sebelum proses penambangan dimulai, adapun peralatan yang akan dipasang adalah, tripod selang pompa air.

b. Tahap selanjutnya penyemprotan material dekat tripod menggunakan pompa dan air yang berasal dari kolam penampungan.

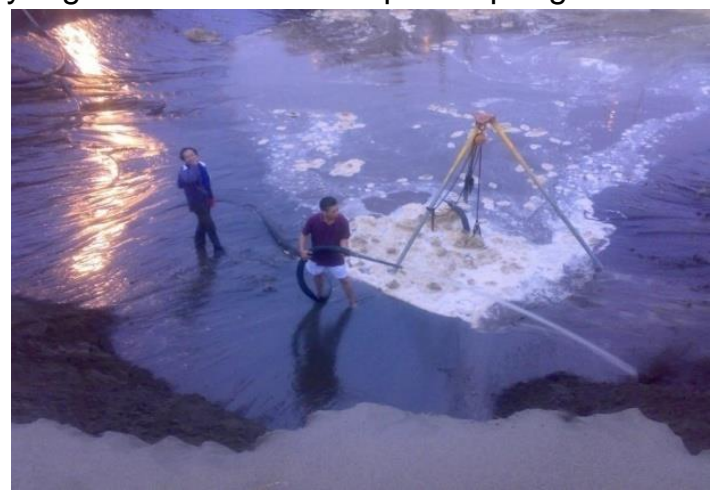

Gambar 3. Pelunakan material sebelum dinaikan kealat magnetit separator

c. Tahap selanjutnya menaikan material pasir besi mesin magnetic separator dengan menggunakan pompa. 
d. Pada sieve trommol terjadi pemisahan antara pasir besi dengan pengotor. Kotoran dialirkan ke lahan yang telah ditambang (back filling), sedangkan pasir besi terus mengalir ke drum magnet.

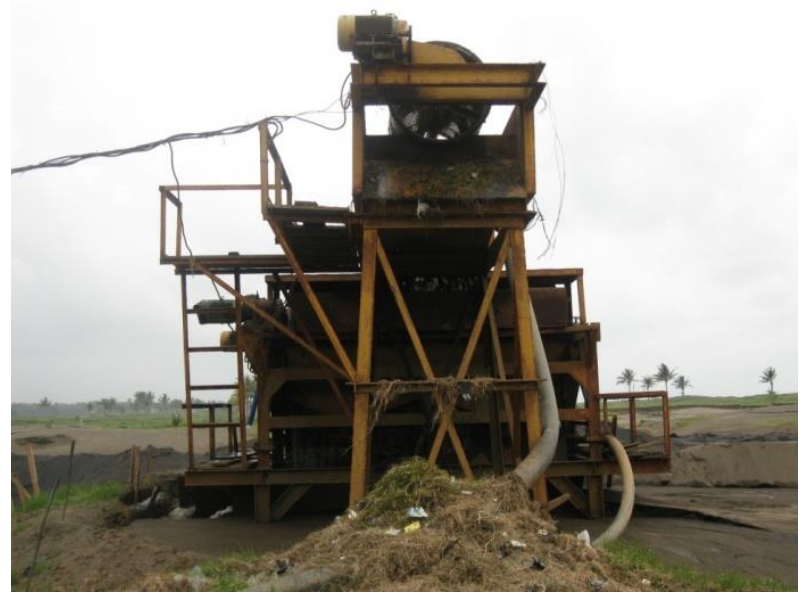

Gambar 4. Pemisahan material pengotor pada sieve trommol

e. Pada drum I (DM I) terjadi pemisahan antara pasir yang mengandung pasir besi dengan pasir biasa. Konsentrat drum magnet I dialirkan ke drum II (DM II), sedangkan tailing drim magnet I ditampung dalam bak tailing.

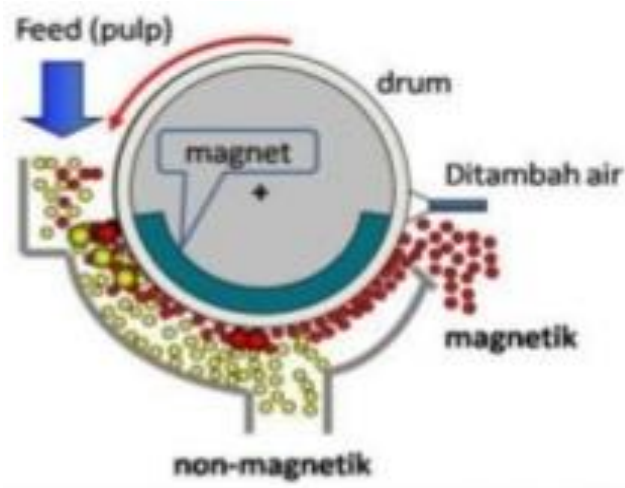

Gambar 5. Simulasi drum magnetit separator

f. Pada drum II terjadi lagi pemisahan, konsentrat DM I dipisahkan pada DM II dan menghasilkan konsentrat DM II yang merupakan konsentrat hasil akhir, sedangkan tailing DM II ditampung bersama-sama dengan tailing DM I pada bak tailing yang kemudian dipompakan ke kolong-kolong bekas penambangan.

g. Tahap penumpukan material pasir besi, pasir besi hasil pemisahan yang keluar dari mesin magnetic separator akan ditampung dalam stock pile yang berada dalam lokasi operasi, sebelum diangkut menggunakan truk ke tempat tujuan yaitu pabrik semen PT. Holcim Indonesia Tbk.

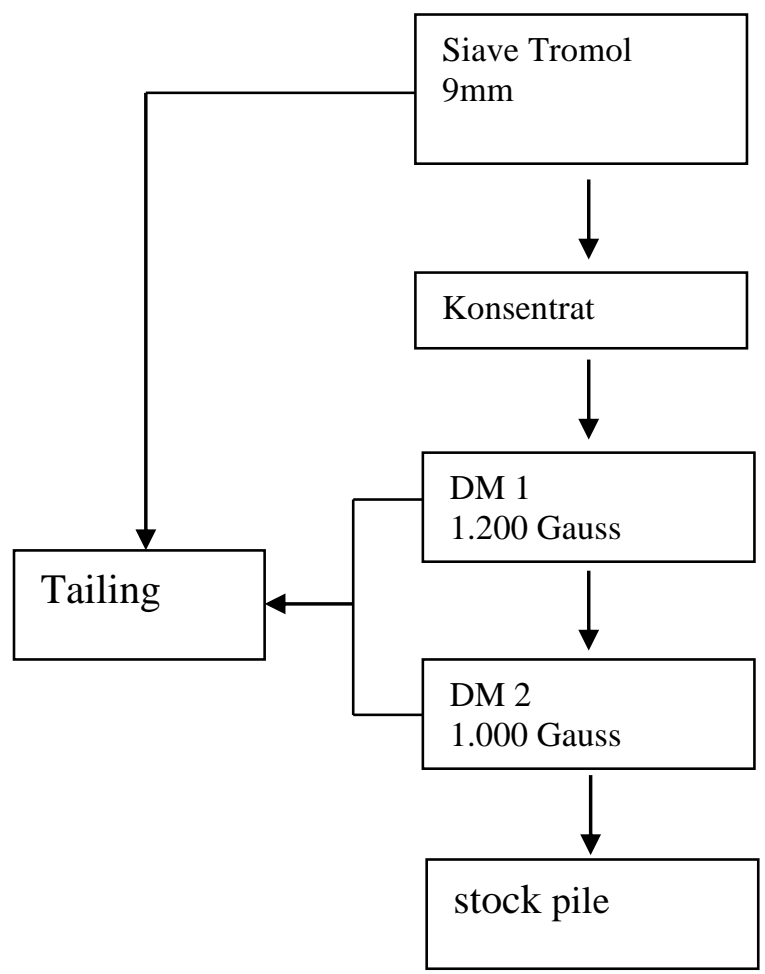

Gambar 6. Proses kerja pada magnetit separator

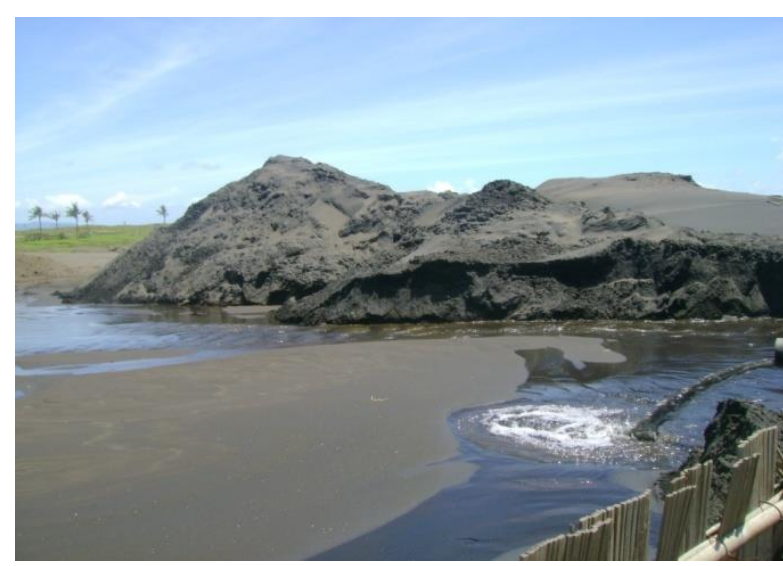

Gambar 7. Tahap akhir pada stock pile penembangan pasir besi

h. Tahap pemanfaatan sisa olahan, material residu/sisa olahan dari proses pengolahan pasir besi diperkirakan sebesar $25 \%$ dari Raw material yang berupa pasir biasa dan pengotor yang keluar dari mesin magnetic separator di alirkan ke tail pile yang nantinya akan dimanfaatkan untuk mengisi kembali daerahdaerah yang telah digali/dirambang (back filing).

Pasir besi yang telah terpilah dan ditimbun dalam stock pile diantaranya dikirim ke pabrik semen PT. Holcom Indonesia Tbk menggunakan 
truck dengan bak tertutup berkapasitas 10 ton sesuai dengan kemanpuan kelas jalan. Pengangkutan diupayakan dilakukan diluar jam sibuk untuk menghindari kemacetan lalulintas.

Kegiatan yang dilakukan pada tahap pasca operasi produksi adalah kegiatan pasca tambang dan penutupan tambang yang meliputi kegiatan reklamasi (mengembalikan kembali area bekas tambang seperti sedia kala).

\section{KESIMPULAN}

Berdasarkan hasil yang didapatkan di lapangan, maka penulis dapat menyimpulkan bahwa:

1. Proses tahapan penambangan dalam pasir besi adalah menyediakan alat-alat dan perlengkapan yaitu :
a. 1 unit pompa hisap
b. Pipa HDPE
c. 1 unit magnetic separator

2. Adapun cara kerja alat untuk mengeksploitasi pasir besi yaitu :

a. Konsentrat pasir akan di hisap naik ke alat magnetic separator

b. Terjadi pemisahan antara kotoran yang bercampur dengan konsentrat pasir pada sieve/scener trommol.

c. Konsentrat pasir akan turun pada drum magnetic I yang di putar menggunakan tenaga dynamo listrik, dan di butuhkan tenaga air untuk memindahkan konsentrat yang mengandung pasir besi ke drum magnetic II, kemudian konsentrat pasir besi akan masuk dalam bak penampungan yang telah di sediakan.

d. Konsentrat pasir yang tidak mengandung pasir besi (DM I dan DM II) akan turun kebawah dan di pompa ke bekas penambangan sebelumnya untuk menutupi lobang-lubang yang sebelumnya telah di tambang.

3. Adapun target produksi dari PT. Bhineka Bumi sendiri adalah 8.000-9.000 Ton/Bulannya. Dari hasil produksi perbulannya PT. Bhineka Bumi dapat menghasilkan 7.000-7.500 Perton konsentrat pasir besi, yang mana hasil produksi pasir besi PT. Bhineka Bumi menjual pada PT. Holcil Indonesia sebagai campuran semen.

\section{UCAPAN TERIMA KSIH}

Penulis mengucapkan banyak terima kasih kepada:
1. Bapak Suriah Lukiman selaku pemilik PT. Bhineka Bumi yang telah memberikan kesempatan untuk melakukan penelitian.

2. Ibu Prastuti Ari selaku pembimbing lapangan selama melaksanakan penelitian.

3. Kedua orang tua yang banyak mendukung dalam langkah menjadi manusia yang baik dan berguna bagi orang lain.

\section{DAFTAR PUSTAKA}

Afdal \& Niarti, L. 2013, Karakteristik Sifat Magnetit Dan Kandungan Mineral Pasir Besi Sungai Batang Kuranji Padang Sumatra Barat, Pp 24-30.

Jumaida, J,. Wahyu, W \& Makhtar, 2013,.Pengaruh Suhu Sintering Terhadap Struktur Dan Sifat Magnetit Material MnZn Ferit, Jateng \& DIY, Yogyakarta. ISSN.

Nurhidayatullah, 2016,. Karakteristik Material Pasir Dengan Menggunakan X-RAY DIFFRACTION (XRD) Dipantai Marina Kab. Bantaeng. UIN Alaudin Makassar.

Rochman, Dkk, 2012,."Review Pengembangan Teknologi Pengolahan Sumber Daya Pasir Besi Menjadi Produk Besi/Baja, Pigmen, Bahan Kramik, Magnet Dalam Mendukung Industri Nasional".Prosiding Insinas.

Kepmen No: 555.K/26M.PE/1995, "Direktur Jendral Pertambangan Umum"

Sukandarrumidi. 2014. "Geologi Umum". Yogyakarta, Gadjah Mada University Press.

Undang-Undang Nomor 32 Tahun 2009 "Tentang Perlindungan Dan Pengolahan Lingkungan Hidup. 
